\title{
A study exploring the attachment pattern and parenting style in adolescent males with Obsessive Compulsive Disorder (OCD)
}

\section{Aparajita Chakraborty ${ }^{1}$, Bidita Bhattacharya ${ }^{2}$}

1. Department of Clinical Psychology, Amity University, Kolkata

2. Department of Clinical Psychology, Institute of Psychiatry, Kolkata

\section{ABSTRACT}

\section{Background}

Attachment pattern and Parenting Style are related and has its impact on different aspects of life. Attachment behaviour anticipates a response by the attachment figure which will remove threat or discomfort. Parenting style, on the other hand, is how parents take care of their child. This impacts the child's personality development, social interaction and close relationships, as well as developing psychopathology. It also influences attachment related insecurities in children and adolescents. Acting together, they often give rise to psychopathological condition, namely obsessive compulsive disorder (OCD).

\section{Materials and Methods}

The study focuses on two separate groups consisting of 20 adolescent (13-17 years of age) males with obsessive compulsive disorder (OCD) and their parents (40, between 40 and 50 years of age) (group 1 - study group), and 40 adolescent males without any overt psychopathology and their parents (120) (group 2 - comparative group). The participants were assessed on General Health Questionnaire12 (GHQ-12),Children Yale-Brown Obsessive Compulsive scale (CYBOCS), Children Depression Inventory-2 (CDI-2), Parenting Style Questionnaire (PSQ) and Adolescent Attachment Questionnaire (AAQ). Obtained data were analyzed by suitable statistical measure by using SPSS.

\section{Results}

Attachment pattern having angry distress and availability were found to be statistically significant in both the groups $(\mathrm{t}=2.11,(\mathrm{P}=0.05)$ and $\mathrm{t}=2.70(\mathrm{P}=0.01)$, respectively. Also authoritarian parenting style in fathers $(t=3.45, P=0.01)$ and authoritative and permissive parenting style in mothers $(t=6.39$, and $t=4.03(P=0.01)$, respectively) of both the groups were statistically significant.

\section{Conclusion}

Angry distress and availability attachment pattern and all three parenting styles play a role in developing obsessive compulsive disorder (OCD) among adolescent males.

Keywords : Attachment, Parenting, Adolescents, Obsessive Compulsive Disorder (OCD).

\section{Address for correspondence :}

Dr. Bidita Bhattacharya

Associate Professor, Department of Clinical Psychology

Institute of Psychiatry, Kolkata

\section{INTRODUCTION}

Exploring the etiological factors of mental disorders has always been a battle field. On one side were the biological understanding believing in biochemical and genetic factors behind the genesis 
The attachment pattern and parenting style in Obsessive Compulsive Disorder (OCD)

of mental disorders while on the other side were the psychological and social understanding of the origin, course and outcome of mental disorders. However, it is needless to say that psychosocial factors are one of the most important aspects of developing and maintaining any psychopathology. Attachment relationships beyond childhood have an important functional role in the overall adjustment of the individual. ${ }^{[1,2,3]}$ A major reorganization of these relationships occurs during adolescence and become the basis for stable reciprocal attachment relationships later in life. Available research has consistently identified the quality of family relationships as well as parenting style in the etiology of emotional disorders in adolescence.

Parenting style can be defined as the way parents take care of their child and which impacts the child's personality development, social interaction and close relationships with significant other. As per Baumrind ${ }^{[4]}$, authoritative parenting style is sensitive and involved in their child's activities, responsive to their needs. Authoritarian parenting style is often characterized as having low acceptance and high control on their children. The permissive parents make few demands, lack of control and use minimal punishment. Since parenting style provides the context for parent child interaction thus it is expected that parenting style could influence attachment related insecurities in children.

Parenting behavior is a crucial factor that influences children's mental health as well as personality formation, and it may predict the problems of children's obsession, anxiety and depressive emotions. Baumrind ${ }^{[4]}$ proposed that different parenting styles have vary in greper cussions for the development of children. Another study by Abramowitz et $\mathrm{al}^{[5]}$ showed that there is a link between authoritarian parenting style and the development of obsessive compulsive disorder (OCD). According to a study by Timpano et al ${ }^{[6]}$ also indicated that the authoritarian parenting style was significantly associated with both obsessive- compulsive symptoms and beliefs (e.g., beliefs about the importance of thoughts and personal responsibility). However, a study showed that there was no significant difference among parenting styles (permissive, authoritative and restrictive Styles) and features of Obsessive Compulsive Disorder (OCD) ${ }^{[7]}$

Previous research have showed that attachment theory is pertinent for studying emotion regulation and mental health ${ }^{[8]}$ In particular, research on adult attachment processes and individual differences in attachment orientations has provided strong evidence for the anxiety-buffering function of what Bowlby ${ }^{[9]}$ had called the attachment behavioral system and the relevance of attachment-related individual differences for coping with stress, retaining psychological resilience. ${ }^{[10]}$ According to attachment theory, interactions with inconsistent and unreliable attachment figures often interfere with the development of a secure and stable mental foundation; and predispose a person to break down psychologically in times of crisis. ${ }^{[11]}$ Attachment insecurity can therefore be viewed as a general vulnerability to mental disorders, with the particular symptomatology depending on genetic, developmental, and environmental factors. Attachment style refers to the internal "working models" which develops through early relationships with caretakers can have a serious impact on our feelings of insecurity, anxiety, fear, avoidance, and satisfaction in our closest relationships throughout our lives. ${ }^{[12]}$ Another study was conducted a study to test a theoretical model of parental empathy and child attachment. They found that parental empathy was positively related to child attachment security and emotional openness, as well as to child perceptions of parental warmth. ${ }^{[13]}$

Literature also shows that attachment style and obsessive compulsive disorder (OCD) are related. The study by Hall ${ }^{[14]}$ showed significant difference in obsessive-compulsive (OC) symptoms and attachment styles. A study showed high anxiety and high avoidance styles correspond to obsessive- 
The attachment pattern and parenting style in Obsessive Compulsive Disorder (OCD)

compulsiveness. ${ }^{[15]}$ Another study showed that the preoccupied attachment exhibit "intrusive symptoms". ${ }^{16]}$

Attachment pattern and parenting style are related. One's attachment style shows its impacts on different aspects of his life including the attachment style of his or her children. Mothers' representations of earlier attachment may influence the development of her infant's attachment to her. ${ }^{[17]}$ There are evidences that many mental disorders are related to the attachment pattern and parenting style. Depressive symptoms are more common in those who are insecurely attached, ${ }^{[18,19]}$ and some theorists have partly attributed this link to the low self-esteem and high levels of dysfunctional attitudes (rooted in working models) harbored by insecurely attached individuals. ${ }^{[20]}$ In a study on undergraduate students, attachment styles high in the avoidance and anxiety dimensions predicted obsessive compulsive disorder (OCD) related thoughts and symptoms. ${ }^{[21]}$ Another research found that dismissing style was evident in prediagnosed obsessive compulsive disorder (OCD) patients..$^{[22]}$

Based on the understanding of the previous studies, the focus of the current study was on exploring the role of attachment pattern and the parenting style on adolescent males who were diagnosed with obsessive compulsive disorder (OCD).

\section{METHOD}

\section{PARTICIPANTS :}

It is a cross sectional hospital based study consisting adolescent males between 13 and 17 years of age with at least 5 years of formal education and their both parents between 40 and 50 years of age with at least 8 years of formal education in a large metropolitan city in eastern India. 20 adolescent males visiting to outpatient department of Psychiatry were diagnosed having obsessive compulsive disorder (OCD) in a government super-speciality hospital of that metropolitan area by the trained mental health professionals, and their both parents were taken for the study. The study group, i.e., group $1(\mathrm{~N}=60)$ consisting 20 adolescent males and their fathers $(\mathrm{N}=20)$ and mothers $(\mathrm{N}=20)$. In comparative group, i.e., group $2(\mathrm{~N}=120) 40$ adolescent males and their fathers $(\mathrm{N}=40)$ and mothers $(\mathrm{N}=40)$ were included. All the participants were able to comprehend either Bengali, English, or Hindi. Adolescents with any other psychopathology, neurological disorders, major physical illness and disability were excluded from the study group. For the comparative group non clinical participants were taken. Fathers and mothers of study group as well as comparative group were non cinical.

\section{TOOLS:}

\section{SOCIO-DEMOGRAPHIC DATA SHEET:}

A semi structured proforma was used to assess the socio demographic details which includes age, domicile, religion, education, family history of psychiatricillness and nature of obsessivecompulsive disorder (OCD) Symptoms ( for adolescents).

\section{The Children's Yale-Brown Obsessive Compulsive} Scale (CY-BOCS): It is the instrument for assessing symptom severity in older children (i.e., 8-18 years) diagnosed with obsessive-compulsive disorder (OCD). CY-BOCS total score yields a reliable and valid scale for assessing symptom severity in early childhood obsessive compulsive disorder (OCD). ${ }^{[23]}$

General Health Questionnaire (GHQ): The 12-Item General Health Questionnaire (GHQ-12) is the most extensively used screening instrument for common mental disorders, in addition to being a more general measure of psychiatric well-being. Cronbach's alpha was calculated to analyze internal consistency. An alpha value of .76 for the entire sample was found. Standardized Alpha: 0.78 (.75 in the group of women, Standardized Alpha: 0.77, and.76 in the group of men, Standardized Alpha: $0.78)$, indicating satisfactory internal consistency in all the groups. ${ }^{[24]}$ 
The attachment pattern and parenting style in Obsessive Compulsive Disorder (OCD)

Adolescent Attachment Questionnaire (AAQ): The AAQ is a self-report questionnaire consisting of 3 scales of 3 statements each, with Likert-type responses from strongly disagree to strongly agree. Studies show that Cronbach's alpha for this measure ranges from .62 to .80 , indicating a satisfactory degree of internal consistency. The AAQ also demonstrates high convergent validity with the Adult Attachment Interview (AAI). ${ }^{[25]}$

Parenting Style Questionnaire (PSQ): This is a 30-item measure of parenting style. PSQ measures parenting style on three subscales of authoritative parenting style, authoritarian parenting style and permissive parenting style. Cronbach alpha for the three scales were found to be $0.91,0.86$ and 0.75 respectively. ${ }^{[26]}$

\section{PROCEDURE:}

Adolescents attending to the Psychiatry out patient department and were diagnosed having obsessive compulsive disorder (OCD) by the trained mental health professionals and gave consent to participate in the study were interviewed in detail following the socio-demographic data sheet. After the detail interview, CY-BOCS was administered and participants who scored more than 8 were further administered GHQ-12. Participants who scored less than 6 on GHQ-12 were finally taken for the study. The final group of the participants were then administered Adolescent Attachment Questionnaire (AAQ). Parents of the adolescents both father and mother were initially administered GHQ-12. Participants who scored less than 6 on GHQ-12 were then taken for the study. The final group of participants were then administered Parent Style Questionnaire (PSQ). Obtained data were analyzed by suitable statistical measure by using SPSS.

\section{RESULT}

The study is being conducted to explore the role of attachment pattern and parenting style in adolescent males with obsessive compulsive disorder (OCD).
The study group and Comparative group have been compared with the help of $t$ test on the basis of age and average year of education (Table 1 ). The $t$ value shows that significant difference exists between the two groups in terms of age. Mean age of the participants for the adolescents having obsessive compulsive disorder (OCD) was around 13 years and that of the comparative group (adolescents without having psychopathology) was around 16years. However, it also shows that the groups are not statistically significant in terms of average year of education.

Table 1: Showing the socio-demographic details of the two groups of adolescents.

\begin{tabular}{|c|c|c|cc|}
\hline $\begin{array}{c}\text { Socio- } \\
\text { demographic } \\
\text { variable }\end{array}$ & Group1 & Group 2 & t value & p value \\
\cline { 2 - 4 } & mean \pm sd & mean \pm sd & & \\
\hline Age & $13.95 \pm 0.86$ & $16.22 \pm 2.03$ & 2.08 & $*(.05)$ \\
\hline $\begin{array}{c}\text { Average year } \\
\text { of education }\end{array}$ & $14.57 \pm 16.89$ & $15.48 \pm 14.65$ & 1.59 & \\
\hline
\end{tabular}

The groups are then compared on the basis of attachment pattern (Table 2). The $t$ value shows that the attachment pattern related to angry distress and availability are significantly different between the two groups. It can be stated that attachment pattern having Angry distress and Availability characteristics play a role in developing obsessive compulsive disorder (OCD) among adolescents.

Table 2: Showing the attachment pattern of the two groups

\begin{tabular}{|l|ll|ll|}
\hline $\begin{array}{l}\text { Attachment } \\
\text { pattern }\end{array}$ & Mean \pm SD & t-value & pvalue \\
\hline Angry distress & $11.38 \pm 3.21$ & $7.30 \pm 3.37$ & 2.11 & ${ }^{*}(0.05)$ \\
\hline Availability & $11.65 \pm 2.79$ & $8.35 \pm 2.45$ & 2.70 & ${ }^{* *}(0.01)$ \\
\hline $\begin{array}{l}\text { Goal Corrected } \\
\text { Partnership }\end{array}$ & $11.32 \pm 2.76$ & $9.45 \pm 2.91$ & 1.31 & \\
\hline
\end{tabular}

The two groups of parents are found to differ significantly when compared in terms of Parenting Style (Table 3). Fathers' and mothers' parenting style were compared between two groups. The $t$ test 
The attachment pattern and parenting style in Obsessive Compulsive Disorder (OCD)

value shows the difference between authoritarian parenting style in fathers and authoritative and permissive parenting style in the mothers. This suggests that features of authoritarian parenting style of the fathers and authoritative and permissive parenting styles of mothers are integral determiners of the disorder.

Table 3: Showing the Parenting Style of both the parents of the two groups

\begin{tabular}{|c|c|c|c|c|c|c|}
\hline \multirow{3}{*}{ Parenting Style } & \multicolumn{2}{|c|}{ Group 1} & \multicolumn{2}{|c|}{ Group 2} & \multicolumn{2}{|c|}{ t value } \\
\hline & Father & Mother & Father & Mother & \multirow{2}{*}{ Father } & \multirow{2}{*}{ Mother } \\
\hline & Mean \pm SD & Mean \pm SD & Mean \pm SD & Mean \pm SD & & \\
\hline Authoritarian & $2.58 \pm 0.78$ & $2.79 \pm 0.94$ & $4.35 \pm 1.13$ & $4.78 \pm 1.39$ & $3.45^{* *}(0.01)$ & 1.17 \\
\hline Authoritative & $2.73 \pm 0.38$ & $2.10 \pm 0.31$ & $4.20 \pm 1.19$ & $4.83 \pm 1.11$ & 0.008 & $6.39^{* *}(0.01)$ \\
\hline Permissive & $2.70 \pm 0.30$ & $2.25 \pm 0.83$ & $4.60 \pm 1.16$ & $4.25 \pm 1.17$ & 0.0001 & $4.03^{* *}(0.01)$ \\
\hline
\end{tabular}

\section{DISCUSSION}

Human infants are born with a repertoire of behaviors (attachment behaviors) "designed" by evolution to assume proximity to supportive others (attachment figures) who are likely to provide protection from threats, promote healthy exploration of the environment and help the infant learn to regulate emotions effectively. Thus, the present study explores the role of the attachment patterns and parenting styles in development of obsessive compulsive disorder (OCD) in adolescent males.

Though childhood and adolescence is often conceptualized as a comparatively untroubled period of life, recent research shows that 32 percent of 13-18 years old suffered from anxiety disorder. [27] 13 percent of 12-17 years old suffered from Depression $^{[28]}, 3$ percent of 13-18 years old suffered from Eating Disorder. ${ }^{[29]}$ Initially, incidence of OCD was restricted to adults, however recent epidemiological studies show $0.25 \%-4 \%$ prevalence of Obsessive Compulsive Disorder (OCD) among children and adolescents. ${ }^{[30,31,32]}$ Increasing demands, stressful life, along with familial disturbances are some of the probable causes of such alarming situation.
Attachment provides a unique relationship with another individual who is perceived as available and responsive and who is turned to for emotional and instrumental support. ${ }^{[25]}$ According to attachment theory, interactions with available and supportive attachment figures impart a sense of safety, trigger positive emotions (e.g., relief, satisfaction, gratitude, love), and provide psychological resources for dealing with problems and adversities. ${ }^{[10]}$ One of the subdomain in AAQ is availability, which indicates that not only the attachment figure be available but that he or she also needs to be perceived as willing to act responsively, dealing effectively with attachment related anxiety. This scale assesses the extent to which the adolescent has confidence in the attachment figure as reliably accessible and responsive to most of his/her attachment needs. Whereas angry distress as a scale in AAQ taps negative affective responses to the perceived unavailability of the attachment figure. ${ }^{[25]}$ In this study, attachment pattern related to the availability and angry distress were found to be statistically significant. Hence, it can be said that adolescent with OCD did not perceive his attachment figure as willing to act responsively when needed. It is well 
The attachment pattern and parenting style in Obsessive Compulsive Disorder (OCD)

documented in previous studies have that insecure children as well as adults evidence higher rates of psychopathology and have stated that the quality of the attachment relationship strongly predicts a variety of child outcomes, and often plays a pivotal role in childhood anxiety. ${ }^{[33,34]}$

When parental behavior fails to make children feel safe, secure, and able to trust the parents in times of need, then children often have difficulty to regulate their emotions and fulfill their needs adaptively, thereby developing negative, insecure views of themselves and others. Along with physical availability, the parents are required by the child to act responsively to the needs. In Indian scenario, children often feel 'threatened' by the controlling and reprimanding nature of parents, though they yearn for their presence as well. ${ }^{[35,36]}$ Researches suggest that insecure parent-child interactions, which make children' uncertain' of the degree to which they are loved, wanted or worthy, can lead them to develop opposing self-perceptions, such as lovable or unlovable, often leading to obsessive compulsive disorder (OCD). ${ }^{[37]}$

Different parenting styles manifest different interactions between parents and their children and these interactions may impact the development of behaviors in the children they are raising. ${ }^{[4]}$ The authoritarian parent attempt to control, and evaluate the behaviour and attitudes of the child in with a set standard of conduct, which is absolute in nature, and formulated by a higher authority. ${ }^{[4]}$ Whereas, authoritative parents attempt to direct the child's activities in a rational issue- oriented manner. Both autonomous self- will and disciplined conformity are valued by the authoritative parent. ${ }^{[4]}$

In current study, statistically significant difference found in authoritarian parenting style in fathers and authoritative and permissive parenting style in mothers of both the groups, suggesting the integral role of these parenting styles on the development of obsessive compulsive disorder (OCD). Research showed that there is a link between an authoritarian parenting style and the development of obsessive compulsive disorder (OCD). ${ }^{[38]}$ Authoritarian parenting style was also found to be associated with anxiety disorders in childhood. ${ }^{[39]}$ Owing to the nature of the authoritarian style which is strict, rigid, low in warmth, and expectance of complete obedience of children, such perfectionist tendency in adolescents are often found as they often try to 'please' their strict parents. This perception is also prevalent in Indian scenario where the fathers are strict regarding rules and regulation and has a controlling attitude, often signaling anxiety. It is in support of previous finding that showed rejection and lack of empathy from father was strongly associated with obsessive compulsive disorder (OCD). ${ }^{[40]}$ Navigating the vulnerable phase of adolescence is dependent on the parent-child relationship during the early formative years. The emotional ambience provided by the family during early years may influence the security and stability. As the key features of authoritative parenting style are desire to provide a safe, emotionally stable, and secure environment for children, individuals growing up with this parenting style are more social, more emotionally confident to combat stress. ${ }^{[41]}$ The leniency as well as the desired quantity and quality of warmth by the mother makes the children emotionally stronger. ${ }^{[41]}$

Permissive Parenting is characterized by warm, nurturing and affectionate toward their children, while being very loose and flexible in setting ground rules and guidelines for their children. ${ }^{42]}$ Permissive parent attempts to behave in a non punitive, acceptant, and affirmative manner toward the child's impulses, desires, and actions. ${ }^{[4]}$ Possible effects on children's development with this parenting style include aggressive reactions by individuals when not getting what they want, and have difficulty in cultivating good relationships with people of authority, and not understanding the concept or merit of both externally applied discipline and self-discipline. ${ }^{[4]}$ Previous studies found that lack of autonomy in permissive parenting results in individuals giving precedence to internal 
thoughts and heightened sense of responsibility was developed, triggering episodes of anxiety and resultant obsessive behaviours. ${ }^{[6]}$ Maternal control and psychological dominance are found to be important predictors for obsessive compulsive disorder (OCD). ${ }^{[43]}$ Current findings are also in support of the previous studies.

\section{CONCLUSION}

Thus, the present study explores the role of attachment and parenting style in adolescent males with obsessive compulsive disorder (OCD) beginning early in life can have serious functional consequences. study reveals that angry distress and availability attachment pattern and authoritative, authoritarian as well as permissive parenting styles playroleasimportantdeterminersof the development of obsessive compulsive disorder (OCD). The role of attachment pattern, parenting style on adolescent with obsessive compulsive disorder (OCD) and will help in providing a new perspective on the dynamics of the psychopathology and thereby delve to design appropriate intervention strategy. However, the interaction among attachment pattern and parenting style and their effect on development of obsessive compulsive disorder (OCD) can be further explored in both the genders with larger sample size.

\section{REFERENCE}

1. Ainsworth MDS. Attachments across the life span. Bulletin of the New York.1985. Academy of Medicine, 61, 792-811.

2. Weiss R. Attachment in adult life. In C. M. Parkes, J. Stevenson-Hinde, \& P. Marris (Eds.). Attachment across the life cycle. 1991. (pp. 171-184). London: Routledge.

3. West ML, Sheldon-Keller, AE. Patterns of relating: An adult attachment perspective. New York: Guilford Press. 1994.

4. Baumrind D.Effects of Authoritative Parental Control on Child Behavior, Child Development, 1966. 37(4), 887-907.

5. Abramowitz JS, Khandker M, Nelson,C, Deacon B, Rygwall R. The role of cognitive factors in the pathogenesis of obsessions and compulsions: A prospective study . Behaviour Research and Therapy. 2006.44, $1361-1374$.

6. Timpano KR, Keough ME, Mahaffey B, Schmidt, NB, Abramowitz, J. Parenting and obsessive compulsive symptoms: Implications of authoritarianparenting. Journal of Cognitive Psychotherapy, 24, 151-164. 2010. doi:10.1891/0889-8391.24.3.151.
7. Strunck HV. Exploration of the Relationship between Obsessive Compulsive Disorder (OCD) and Parenting Style Subtypes. Walden University. Walden Dissertation and Doctoral Studies. 2016.

8. Bowlby J. Attachment and loss, Vol. 2. Separation: anxiety and anger. New York: Basic Books, 1973.

9. Bowlby J. Attachment and loss, Vol. 1. Attachment (2nd ed.). New York: Basic Books, 1982.

10. Mikulincer M, Shaver PR. Attachment in adulthood: structure, dynamics, and change. New York: Guilford, 2007

11. Bowlby J. A secure base: clinical applications of attachment theory. London: Routledge, 1988.

12. Firestone L. How Your Attachment Style Affects Your Parenting Experiencing an insecure attachment pattern as a child can hurt us in many ways. Posted Oct 19, 2015.

13. Stern JA, Borelli JL, Smiley, PA. Assessing parental empathy: a role for empathy in child attachment. Attach Hum Dev. 2015;17(1) : 1-22.

14. Hall N, Smith E, Linders J, Aquino T. Adult Attachment Style, Obsessive-Compulsiveness, and Response to a Stressful Situation. Westminster Journal for Global Progress. 2017.

15. Doran G, Moulding R, Kyrios M, Nedeljkovic M, Mikulincer M. Adult attachment insecurities are related to obsessive compulsive phenomena. Journal of Social and Clinical Psychology. 2009. 28(8), 1022-1049.

16. Kemp MA, Neimeyer GJ. Interpersonal Attachment: Experiencing, Expressing, and Coping with Stress. Journal of Counseling Psychology, 1999. 46(3) 388-394.

17. Shah PE, Fonagy P, Strathearn L. Is attachment transmitted across generations? The plot thickens. Clinical and Child Psychology. 2010 Jul; 15(3) : 329-45.

18. Carnelley KB, Pietromonaco PR JaffeK. Attachment, caregiving, and relationship functioning in couples: Effects of self and partner, Personal Relationships, 3(3), 257-277. 1996.

19. Simpson JA, Rholes WS, Campbell L, Tran S, Wilson CL. Adult attachment, the transition to parenthood, and depressive symptoms. Journal of Personality and Social Psychology, 84, 1172-1187. 2003.

20. Roberts JE, Gotlib IH, Kassel JD. Adult attachment security and symptoms of depression: The mediating roles of dysfunctional attitudes and low self-esteem. Journal of Personality And Social Psychology, 70(2), 310-320. 1996.

21. Rezavana S, Bahrambib F, Abedib M, MacLeodc C, Neshat Doostb HT, Ghasemi V. Attachment insecurity as a predictor of obsessive-compulsive symptoms in female children. Counselling Psychology Quarterly, 25(4), 403-41. 2012.

22. Ivarsson T, Granqvist P, Gillberg C, Broberg AG. Attachment states of mind in adolescents with obsessive-compulsive disorder and/or depressive disorders: A controlled study. European Child \& Adolescent Psychiatry, 19(11), 845-853. 2010.

23. Gallant J, Storch EA, Merlo LJ, Ricketts ED. Convergent and discriminant validity of the Children's Yale-Brown Obsessive Compulsive Scale-Symptom Checklist. Journal of Anxiety Disorders. 22(8) : 1369-76. 2008. 


\section{The attachment pattern and parenting style in Obsessive Compulsive Disorder (OCD)}

24. Goldberg D. General Health Questionnaire (GHQ 12). Windsor: NFER-Nelson. 1992.

25. West M, Rose MS, Sheldon-Keller A, Adam K. Adolescent AttachmentQuestionnaire: A Brief Assessment of Attachment in Adolescence. Journal of Youth and Adolescence. October 1998, Volume 27, (5), pp 661-673.

26. Robinson CL, Mandleco B, Olsen SF, Hart CH. Authoritative, authoritarian, and permissive parenting practices: Development of a new measure. Psychological Reports, 77, 819-830. 1995.

27. U.S. Department of Health and Human Services, National Institute of Mental Health. Transforming the understanding and treatment of mental illness. [Internet]. 2017 Nov. Available from: https://www.nimh.nih.gov/health/ statistics/any-anxiety-disorder.shtml.

28. U.S. Department of Health and Human Services, National Institute of Mental Health. Transforming the understanding and treatment of mental illness.[Internet]. 2019 Feb. Available from : https://www.nimh.nih.gov/health/statistics/majordepression.shtml.

29. U.S. Department of Health and Human Services, National Institute of Mental Health. Transforming the understanding and treatment of mental illness.[Internet]. 2017Nov. Available from: https://www.nimh.nih.gov/health/statistics/eatingdisorders.shtml.

30. Flament MF, Whitaker A, Rapoport JL, et al. Obsessive compulsive disorder in adolescence: an epidemiological study. J Am Acad Child Adolesc Psychiatry 1988; 27 : 764-71.

31. Heyman I, Fombonne E, Simmons H, et al. Prevalence of obsessive-compulsive disorder in the British nationwide survey of child mental health. Br J Psychiatry 2001; 179 : 324-9.

32. Douglass HM, Moffitt TE, Dar R, et al. Obsessive-compulsive disorder in a birth cohort of 18-year-olds: prevalence and predictors. J Am Acad Child Adolesc Psychiatry 1995; 34 : 1424-31.

33. Greenberg MT. Attachment and psychopathology in childhood. In: Cassidy J, Shaver PR, editors. Handbook of attachment: Theory, research, and clinical implications. New York: Guilford; 1999. pp. 469-96.
34. Muris P, Mayer B, Meesters C. Self-reported attachment style, anxiety and depression in children. Soc Behav Pers. 2000; 28 : 157-62.

35. Sondhi R.Parenting Adolescents in India: A Cultural Perspective. 2017. Available from: http:/ /dx.doi. org/10.5772/66451.2017.

36. Akhtar Z. The Effect of Parenting Style of Parents on the Attachment Styles of Undergraduate Students Zarina, Ph.D. Volume $12: 1$ January 2012.ISSN 1930-2940. Language in India.

37. Guidano VF, Liotti G. Cognitive processes and emotional disorders. New York: The Guilford Press; 1983. pp 347.

38. Abramowitz JS, Beacon BJ, Olatunji BO, Wheaton MG, Berman NC, Losardo D, et al., Assessment of obsessivecompulsive symptom dimensions: Development and evaluation of the Dimensional Obsessive-Compulsive Scale. Psychological Assessment, 22, 180-198. 2010. doi:10.1037/ a0018260.

39. Wood JJ, McLeod BD, Sigman M, Hwang WC, Chu BC. Parenting and childhood anxiety: Theory, empirical findings, and future directions. Journal of Child Psychology and Psychiatry, 44, 134-151. 2003. doi: 10.1111/1469-7610.00106.

40. Alonso PM, Menchón J, Mataix-Cols D, Pifarré J, Urretavizcaya M, Crespo JM, et al. Perceived parental rearing style in obsessive-compulsive disorder: Relation to symptom dimensions. Psychiatry Research 2004; 127(3) : 267-78

41. Uji M, Sakamoto A, Adachi K, Kitamura T. The impact of authoritative, authoritarian, and permissive parenting styles on children's later mental health in Japan: Focusing on parent and child gender. Journal of Child and Family Studies, 23, 293-302. 2014. doi : 10.1007/s10826-013-9740-3.

42. Williams KE, Ciarrochi J, Heaven PCL. Inflexible parents, inflexible kids: A 6-year longitudinal study of parenting style and the development of psychological flexibility in adolescents. Journal of Youth and Adolescence, 41, 10531066.2012. doi:10.1007/s10964-012-9744-0.

43. Aycicegi A, Harris CL, Dinn WM. Parenting style and obsessive-compulsive symptoms and personality traits in a student sample. Clinical Psychology and Psychotherapy 2002;9(6):406-17 